\title{
Netzwerk Teilchenwelt: Coordinated Outreach and Recruitment of Young Talents in Germany
}

\author{
Uta Bilow $^{a,{ }^{*}}$ and Michael Kobel ${ }^{a}$ \\ ${ }^{a}$ Technische Universität Dresden, Institute for Nuclear and Particle Physics \\ 01062 Dresden, Germany \\ E-mail: uta.bilowetu-dresden.de, michael.kobel@tu-dresden.de
}

Netzwerk Teilchenwelt is a Germany-wide outreach program comprising 30 universities and research labs. About 150 researchers are involved, bringing cutting edge science into the classroom. 3500 high school students each year take the opportunity to work with original data from HEP experiments in special masterclasses or to study cosmic particles with detectors. On advanced levels, motivated students continue to engage in research and attend workshops at CERN or conduct their research projects. Through a fellow program, highly motivated students are offered early contact with research groups, personal support, and further training. Activities are funded by the German Ministry of Education and Research as an integral part of HEP research. Within the current funding scheme, topics from hadron and nuclear physics are included and links to other projects are created which expand the range of target groups. 


\section{Introduction}

To inspire the next generation of scientists and recruit young talents is an important aim of outreach activities. In Germany, Netzwerk Teilchenwelt [1] has established a program for coordinated outreach in particle and astroparticle physics. 30 universities and research institutes have joined forces with CERN and offer various activities for high school students and undergraduate students, which are organized as a multi-level program. In this way, large numbers of students get an insight into this field of research, meet physicists, learn about topics of current research, the organization, and the process of research. The most motivated students are further encouraged to pursue a career in this field and can participate in research at an early stage of their career.

Netzwerk Teilchenwelt was launched in 2010; the project team works at TU Dresden, DESY in Zeuthen, and CERN. Additional hubs are situated at the Universities of Bonn, Mainz, and Münster.

\section{Offers for high school students}

\subsection{Activities in particle physics}

On the basic level, high school students aged between 15 and 19 can take part in a particle physics Masterclass and analyze data from the LHC experiments ALICE [2][3], ATLAS [4][5], CMS [6], or LHCb [7]. A Masterclass is a 1-day workshop, where students become "particle physicists for a day." They learn more about particle physics from a mentor before making a measurement based on authentic data from a contemporary experiment. These Masterclasses follow the model of the very successful Masterclass program [8] from the International Particle Physics Outreach Group (IPPOG) [9]. They are usually run at classrooms, at school labs, museums, or science centers. In this way, it is sufficient for a physicist to travel to a school, which may be a little further away if necessary. Whole school classes do not have to come to a research institute.

\subsection{Astroparticle physics offers}

Besides the LHC activities, Masterclasses with data from the Pierre Auger Observatory [10] or the IceCube neutrino telescope [11] are also offered. The web portal Cosmic@web [12] provides access to data sets from astroparticle physics experiments, which are located on the research vessel Polarstern or the Neumayer-Station. Netzwerk Teilchenwelt has built special detectors (Cherenkov or scintillation detectors) [13] which are available at the research labs. Students can take their own data with these detectors and perform different measurement tasks that range from 1-day-activities to longer projects.

Every year, about 3.500 high school students take part in the basic program and work with original CERN data or carry out their own measurements with particle detectors. In 2019, a total of 160 Masterclasses have been held in Germany. Every year, about 350 pupils are involved in the higher levels, which are described in the next paragraph. 


\subsection{Workshops and Research Projects at CERN}

Having completed the basic level, the most motivated high school students can take part in a workshop at CERN, where they can gain in-depth experience with research during a 4-daystay. And finally, some particularly committed students prepare their own research work, which they then contribute to their graduation from high school (Abitur, university entrance qualification), for example. For this work, the students can spend up to two weeks working in a research group at CERN, while preparation and follow-up work take place at a research institute near their home. Many of these works have already won prizes in national competitions, such as Jugend forscht [14].

\section{Supporting young talents at university}

In an evaluation of the program, it was found that a considerable proportion of the high school students who had applied to take part in a CERN workshop subsequently started studying physics at university and were still interested in particle physics. Therefore, a so-called Fellow Program [15] has been launched in 2017 in order to support and promote young people during their transition to university. All high school students who had applied to take part in a CERN workshop in previous years were invited to register for the program. The Fellow program currently has about 150 participants. The program offers them access to the particle physics research groups via internships or regulars' tables. These in turn benefit from the fellows' highly motivated and pre-educated students for support in scientific or outreach activities, as well as young scientists for their research groups. The fellows receive an opportunity for nationwide networking via an annual meeting, and they receive professional support via an annual Fellow/Bachelor School in Particle Physics, which was held in spring 2019 for the first time. In spring 2020, it had to be canceled due to the pandemic.

\section{Other groups involved in the program}

\subsection{PhD students}

All activities for high school students are usually guided and supervised by $\mathrm{PhD}$ students as so-called "masters". Currently, about $150 \mathrm{PhD}$ and Master students are engaged in the program. They hold Masterclasses, explain to the students how the particle detectors work, and supervise the student research work. At the same time, they act as role models. In return, they receive a fee and travel expenses. The Masterclasses are normally held in the schools. This reduces the organizational effort and allows the offers of Netzwerk Teilchenwelt to reach the region - they are quasi mobile. Netzwerk Teilchenwelt offers soft skill courses for the $\mathrm{PhD}$ students with contents from science communication, didactics and presentation techniques, which are also beneficial for the further career [16].

\subsection{Teachers}

Teachers are addressed as multipliers via other programs. Here, extensive context and teaching material was developed, such as a four-volume teaching series on particle physics [17], a card game with particle profiles [18] and a new chapter for the physics teaching platform LEIFI-Physik [19], which is very popular among teachers and students in Germany. In addition, 
two-day teacher training courses are held several times a year as well as a one-week summer school for 20 teachers at CERN [20].

\section{Activities in the current funding period}

HEP research in Germany is mainly funded by the German Ministry of Education and Research (BMBF) within the current research framework program Exploration of the Universe and Matter (ErUM). As an innovation, outreach and science communication activities are now included in this program. Netzwerk Teilchenwelt receives funding from this program through a project called KONTAKT as an integral part of research. The aims of the KONTAKT project, in which Netzwerk Teilchenwelt cooperates with the German LHC communication agency Weltmaschine [21], are to open up new target groups such as the general public or journalists, to develop new programs and to integrate topics from hadron and nuclear physics research, which is also funded in this framework program.

A mobile exhibition module is currently under development. The exhibition is to be set up quick, so that it can travel easily throughout the country. The content is targeting groups that are less likely to access science, thus the tour stops are planned in shopping malls, market places and railway stations. In addition, Netzwerk Teilchenwelt has purchased virtual reality headsets and installed apps from several experiments (LHC, Belle II and IceCube). The sets are centrally maintained and loan to the universities and research labs for outreach events. For journalists, a trip to CERN was planned for spring 2020, but had to be postponed due to the pandemic.

The existing offers from Netzwerk Teilchenwelt, which mainly cover LHC physics and astroparticle physics, have been enriched with a Belle II Masterclass [22] and more topics from hadron and nuclear physics, such as a scattering experiment Masterclass [23] and a hadron therapy Masterclass [24][25]. Several exhibits are under development as well as a detector school for Fellows/Bachelor students. A 1-week summer course for high school students at the MAMI accelerator (University of Mainz), planned for 2020, had to be canceled due to the pandemic.

\section{Reactions to the COVID-19 pandemic}

Due to the COVID-19 pandemic, face-to-face events have been virtually impossible. Therefore, in the situation of the lockdown, offers for all target groups were conceptually revised and converted to online variants. Online Masterclasses [26] were offered for high school students. The young people could dial in from home and take part in the Masterclass from there. The content of a project day was divided into two afternoons to accommodate the online format and not overstretch the attention span of the young people.

A well-attended online event was organized for fellows, the so-called neutrino afternoon [27]. After an introductory talk, fellows had a virtual tour to the KATRIN experiment at Karlsruhe Institute of Technology, followed by a lecture on neutrino oscillations and the demonstration of a pendulum as a model for this phenomenon. In addition, there were online social events for the fellows.

The facilitators ( $\mathrm{PhD}$ students) were invited to participate in online trainings. There was a workshop on virtual events [28] and an extended online training on science communication [29]. 
A virtual offer was also created for teachers in the form of a 5-hour training course, From Collision to Discovery [30], which took place twice in 2020.

\section{Conclusion}

Netzwerk Teilchenwelt clearly brings positive effects for all groups involved. High school students can engage in a wide range of activities, from Masterclasses and detector projects to programs at CERN and own research projects. Through the program, interested students are supported according to their inclinations.

Young researchers, mostly $\mathrm{PhD}$ students from the participating universities and research institutes, hold these events for high school students, such as Masterclasses with data from various experiments, or they bring detectors to the classrooms which enable students to take their own data and carry out measurements. The $\mathrm{PhD}$ students experience interest in their research topics and improve their communication and other soft skills.

The fellow program bridges the gap between high school and research groups. Young students can get in close contact with the research groups at an early stage of their career, whereas the research groups can establish contact with promising young talents.

The network approach helps to bundle existing activities as well as to share structures and programs. In this way, a high visibility and impact of the outreach activities is reached.

Integrating outreach into research activities in Germany via the funding program is an important step towards anchoring science communication in research. This serves to attract young researchers, but also promotes the exchange between science and society.

\section{References}

[1] https://www.teilchenwelt.de/.

[2] https://alice-masterclass.web.cern.ch/.

[3] http://www-alice.gsi.de/masterclass/.

[4] https://atlas.physicsmasterclasses.org/en/wpath.htm.

[5] https://atlas.physicsmasterclasses.org/en/zpath.htm.

[6] https://cms.physicsmasterclasses.org/cms.html.

[7] https://Ihcb-public.web.cern.ch/en/LHCb-outreach/masterclasses/en/.

[8] https://www.physicsmasterclasses.org/.

[9] https://ippog.org.

[10] https://www.auger.org/index.php/edu-outreach/event-display .

[11] https://masterclass.icecube.wisc.edu/.

[12] https://physik-begreifen-

zeuthen.desy.de/offers/cosmic_particles/cosmicweb/index_eng.html

[13] https://www.teilchenwelt.de/angebote/astroteilchen-experimente/. 
[14] https://www.jugend-forscht.de/

[15] https://www.teilchenwelt.de/mitmachen/fellows/.

[16] https://www.teilchenwelt.de/mitmachen/vermittler/.

[17] https://www.teilchenwelt.de/material/materialien-fuerlehrkraefte/unterrichtsmaterial-teilchenphysik/ .

[18] https://www.teilchenwelt.de/fileadmin/user_upload/Redaktion/Netzwer k_Teilchenwelt/Downloads/Teilchensteckbriefe_engl.pdf.

[19] https://www.leifiphysik.de/kern-teilchenphysik.

[20] https://www.teilchenwelt.de/angebote/lehrerfortbildungen-forschungtrifft-schule/.

[21] https://www.weltmaschine.de/.

[22] https://belle2.ijs.si/public/.

[23] https://www.schule.physik.uni-mainz.de/streubretter/.

[24] https://indico.cern.ch/event/840212/.

[25] L. Graczykowski, P. Nowakowski, P. Foka, New developments for ALICE MasterClasses and the new Particle Therapy MasterClass, arXiv:2005.02215.

[26] https://indico.cern.ch/event/928010/.

[27] https://indico.cern.ch/event/925927/.

[28] https://indico.cern.ch/event/950753/.

[29] https://indico.cern.ch/event/936023/.

[30] https://indico.cern.ch/event/936443/. 